\title{
Review: Effects of maternal micronutrient supplementation on placental function
}

Kerry Richard $^{1,2,3 \#}$, Olivia Holland ${ }^{4 * \#}$, Kelly Landers ${ }^{1}$, Jessica J Vanderlelie ${ }^{4}$, Pierre

Hofstee $^{4}$, James SM Cuffe ${ }^{4}$, Anthony V Perkins ${ }^{4}$

${ }^{1}$ Conjoint Endocrine Laboratory, Chemical Pathology, Pathology Queensland, Queensland Health, Herston, Qld 4029.

${ }^{2}$ School of Medicine, University of Queensland, Herston, Qld 4029,

${ }^{3}$ School of Biomedical Sciences, Queensland University of Technology, Brisbane, Qld 4000.

${ }^{4}$ School of Medical Science, Menzies Health Institute Queensland, Griffith University, Gold Coast Campus Southport, Queensland, Australia.

\#These authors contributed equally to the work

*Corresponding author:

Olivia Holland

School of Medical Science, Menzies Health Institute Queensland, Griffith University Gold Coast Campus, Parklands Drive, Southport, Qld, 4222, Australia

Phone: + 61 (0) 7 55528970; Fax: + 61 (0) 7 56780795; e-mail: o.holland@ griffith.edu.au 


\begin{abstract}
Pregnancy is a physiological challenge that may require additional nutritional support. Suboptimal micronutrient intakes and micronutrient deficiencies during pregnancy are a global problem, often leading to poor maternal and child outcomes. Micronutrient supplementation is commonly recommended during pregnancy to support and enhance maternal metabolism. Recent studies suggest that the use of multiple micronutrient supplements may be of benefit during a normal pregnancy and may significantly reduce the risk of preeclampsia, preterm delivery, gestational diabetes, and improve pregnancy outcomes. Given the crucial role that the placental plays in mediating pregnancy outcomes, it is important to consider the impact of micronutrient supplementation on the mechanisms associated with placental function, as well as maternal and fetal homeostasis. This review will consider the role of key micronutrients in supporting pregnancy and the possible mechanisms by which multiple micronutrients influence placental function and modulate placental oxidative stress and inflammation.
\end{abstract}

Keywords: micronutrient; supplement; nutrition; pregnancy; placenta; maternal 


\section{Introduction}

Micronutrients are defined as elements and compounds required in very small quantities to exert physiological effects and include numerous vitamins and minerals derived from the diet. Micronutrients are essential for cellular metabolism, optimal tissue function and growth, due to their involvement in the production of enzymes, hormones, signalling molecules, and the regulation of differentiation and apoptosis [1] [2]. An adequate supply of micronutrients during pregnancy facilitates the successful development of the fetus, and supports maternal and placental homeostasis as physiological demands increase across gestation $[3,4]$.

Throughout the course of pregnancy, the requirements of the growing fetus may lead to an increased risk of micronutrient deficiency [5]. Maternal micronutrient deficiencies can have long-term impacts for offspring, including effects on cognition and increased risk of cardio-metabolic disease, in addition to the risk of adverse complication during pregnancy and fetal and maternal mortality [5]. In the developing world, micronutrient deficiencies during pregnancy are common, with poor nutrition associated with both suboptimal perinatal outcomes $[6,7]$, and deficiencies in several key micronutrients linked with the inflammatory processes involved with preterm labour and pre-eclampsia [7]. Antenatal micronutrient supplementation has been shown to improve birth outcomes in areas of inadequate dietary intake [8].

As the site of micronutrient transfer, the placenta is central to the provision of resources to the fetus. Placental transport capacity will adapt across gestation to supply the variable resource demands of the developing fetus $[9,10]$. Several micronutrients are actively transported across the placenta, and fetal nutrient supply can be maintained by the up-regulation of transporters when maternal availability is limited [10]. In addition to 
nutrient transport, the placenta has key roles in the modulation of inflammation and oxidative stress that are also affected by micronutrient sufficiency [11]. This review will consider the evidence to support multiple micronutrient preparations and the role of essential micronutrients including iron, iodine, zinc, folate and selenium in supporting placental function and healthy pregnancy. The role of vitamin A will also be considered due to its importance in supporting fetal development despite its absence from pregnancy specific preparations.

\section{Micronutrients}

\subsection{Multiple micronutrient preparations}

In most developed nations, pregnancy specific multiple micronutrient supplements are widely available and in common use. In a recent study conducted in Australia, it has been estimated that as many as 100,000 pregnant women could be consuming these products per annum [12]. The majority of supplements available on the market contain a combination of $\mathrm{b}$ group vitamins (niacin, riboflavin and thiamine, B12, B6), vitamins $\mathrm{D}, \mathrm{E}$ and $\mathrm{C}$, folate, iron, iodine, copper, selenium and zinc. In addition to this core group of components, a wide variety of vitamins, minerals and herbal preparations are also added with significant variability in formulations evident [12].

Retrospective cohort analysis has suggested that the use of multiple micronutrients during pregnancy may significantly reduce the risk of developing complications of pregnancy including pre-eclampsia [13-15], preterm delivery [7] and other complications [16]. However, despite these findings, and mechanistic evidence of plausible materno-fetal 
health advantages, varied results have been noted upon systematic review of supplementation trials [6]. Such variability may be linked to specific population contexts and resultant supplementation responses [6].

A recent Cochrane review however, analysed 19 trials across low and middleincome countries and concluded that there was a strong basis from which to replace iron and folic acid supplements with multiple micronutrient preparations for pregnant women [8]. Such evidence highlights, that although significant advancements in understanding of micronutrient effects during pregnancy have been made across the past 20 years, there remains gaps in our understanding of the interaction effects of multiple micronutrient supplements and the preparation formulations required for greatest efficacy - which warrant further investigation.

\subsection{Iron}

Globally, iron is one of the most prevalent micronutrient deficiencies and is estimated to affect 32 million pregnant women [17]. During pregnancy iron is required in high levels to support fetal development with supply facilitated by the active transport from the maternal to the fetal circulation against the concentration gradient by the placenta [10]. With fetal demand increasing significantly during late gestation, maternal requirements also elevate and as such the risk of anaemia increases with advancing gestation [17].

In total, the placenta transports approximately $270 \mathrm{mg}$ of iron to the fetus each day, with the iron stored during in utero development the major iron source for the first six months of life[18]. Iron uptake is facilitated via maternal diferric-transferrin binding to and being endocytosed by placental transferrin receptors (TfR) found on the apical syncytiotrophoblast [18]. Iron is then released by the acidification of vesicles and reduced 
by ferrireductases, which are then transported into the cytoplasm by divalent metal transporter 1 (DMT1). Iron can be stored in the cytoplasm as ferritin or transported to the fetal circulation via ferroportin and oxidised by ferroxidase zyklopen/hephaestin like-1 [18].

Placental iron transport can adapt to maternal and fetal iron levels. In women with iron deficiency, placental transport of iron is increased [10], possibly through the increased expression of placental TfR [19]. Indeed, increased expression of TfR leads to increased iron uptake in BeWo cells [19]. Low iron status in rat dams has been evidenced to lead to increased expression of TfR and DMT1, and an increased activity of copper oxidase [19] Low fetal iron levels can also lead to the up-regulation of the placental TfR and DMT1 [18]. The human placenta is thought to rely primarily on the uptake of non-heme iron, however there is some evidence that the placenta may also be able to utilise iron of heme origin [19]. The placenta expresses proteins involved in heme iron uptake and heme scavenger receptors [19]. Despite the up-regulation of placental transporters, low maternal iron levels can compromise fetal iron needs and may lead to altered metabolism and development in offspring, including reduced cognitive function [18].

\subsection{Iodine}

Iodine is essential for thyroid hormone synthesis and thyroid hormone is essential for normal human fetal brain development. Maternal iodine deficiency is the single most preventable cause of mental retardation and brain damage worldwide [1]. In the first and second trimesters, before the fetal thyroid gland is functional, fetal brain development is dependent on the passage of maternal thyroid hormone across the placenta [20]. In areas of severe iodine deficiency, maternal supplementation with iodine prior to conception reduces 
the risk of cretinism [21]. Once the fetal thyroid gland becomes active, it requires placental transfer of iodine in order to synthesize thyroid hormones.

Human trophoblasts express the sodium iodide symporter (NIS) [22, 23] and Pendrin [24] and functional studies have demonstrated that these are responsible for iodide influx and efflux respectively [24]. Pendrin is an anion exchanger [24] and activated by high concentration of intracellular iodide generated by NIS [25]. Placental NIS is localised to the apical membrane of syncytiotrophoblasts, which directly contacts with maternal blood. Conversely, Pendrin is located in the basal membrane of syncytiotrophoblasts and effluxes iodide into the extracellular space [23, 24].

Excess iodide inhibits iodide organification in the normal thyroid gland (WolffChaikoff effect) [26] and is associated with a decrease in NIS mRNA and protein levels [27]. In iodine deficient rats, NIS mRNA is up regulated in fetal thyroid and placenta [28]. In BeWo cells, iodide causes a significant decrease in NIS mRNA and apical membrane protein that is followed by decreased iodide uptake [29]. These studies suggest that selfregulation of iodide uptake by intracellular iodide occurs in thyroid and placenta.

Interestingly, in cases of maternal hypothyroxinaemia and moderate iodide deficiency, neonatal cord blood thyroid hormone levels are significantly higher than maternal levels [30] suggesting that placental NIS expression is increased resulting in increased maternofetal iodide transport. Conversely, excessive maternal iodide intake may down-regulate placental NIS expression and reduce iodide transport to the fetus.

\subsection{Selenium}

Selenium is an essential trace element required to form selenocysteine, which is now widely recognised as the $21^{\text {st }}$ amino acid. Selenocysteines are incorporated into the active 
site of specialised selenoproteins, which have a variety of functions [31]. Currently, 25 selenoproteins have been characterised and these include 6 isoforms of glutathione peroxidase (GPx), 3 isoforms of thioredoxin reductase (TrxR) and 3 iodothyronine deiodinases (DI) [31]. These selenoproteins have important roles to play in fetal development and placental redox homeostasis and emphasise the need for adequate selenium during pregnancy. Other important selenoproteins include selenoprotein $\mathrm{H}$ that is involved in mitochondrial biogenesis and selenoproteins that stabilise the endoplasmic reticulum such as Sel N, Sel S and the recently discovered Sel R [32].

Selenium deficiency has been shown to impact several important biological systems and may lead to a range of pathologies including cardiac myopathy and muscular dystrophy, impaired thyroid metabolism, neurological systems, and male reproductive system [33]. Maternal selenium concentrations have been shown to progressively decline during pregnancy [34] hence the recommendations for increased selenium intake over the course of gestation. In a significant recent publication, Mariath et al presented a systematic metaanalysis of 33 studies which conclusively demonstrated that poor selenium status was correlated with poor pregnancy outcomes including increased incidence of recurrent miscarriage, preeclampsia, intrauterine growth restriction and preterm birth [35].

Selenium is essential for fetal development and placental function and lower levels have been associated with poor pregnancy outcomes [36]. Several key selenoproteins play a role in preventing placental oxidative stress, stabilising trophoblast endoplasmic reticulum and have important endocrine roles. To date there have been 3 randomised control trials examining the efficacy of selenium supplementation on the incidence of preeclampsia [3739]. All have used a supplement containing $60-100 \mu \mathrm{g} /$ day or placebo from $1^{\text {st }}$ trimester to term. However, all 3 trials have been under-powered with only 50-100 patients in each arm of the trial, yet there have been claims of significant benefit. 
Zinc has antioxidant activities and is involved in carbohydrate and protein metabolism, nucleic acid synthesis, cell division and differentiation and therefore plays a critical role in fetal growth and development. Severe zinc deficiency is rare and results in short stature, hypogonadism, impaired immune function, skin disorders, cognitive dysfunction, and anorexia [1]. Inadequate zinc levels have been found to effect placental development in a mouse model, through reduced trophoblast differentiation and protein expression, with resulting reduction in placental weight and size. In humans zinc deficiency has been associated with pregnancy complications such as prolonged labour.

Around $30 \%$ of the world's population is affected by mild to moderate zinc deficiency [1]. Meat (especially shellfish) provides the best source of zinc and so those on plant-based diets are vulnerable to deficiency particularly since high levels of inhibitors (such as fibre and phytates) in the plant based diet can reduce absorption of metallic cations [40]. Mild to moderate deficiency increases susceptibility to infection [41] and is involved in much of the morbidity related to malaria in children [42]. It is estimated that zinc deficiency plays a role in 800,000 deaths per year due to diarrhoea, pneumonia, and malaria in children under five.

Interestingly, the human fetus has higher zinc levels than its mother due to placental zinc transport and zinc binding to placental metallothionein [43]. Several zinc transporters have been identified in human placenta including Zinc Transporter 5 (ZnT5) and human ZnT-like 1 (hZTL1). Similarly to enterocytes, hZTL1/ZnT5 are localised to the apical membrane of the placental syncytiotrophoblasts [43]. However in contrast to enterocytes, which increase transporter expression when exposed to increased levels of zinc [44], human 
placental cells reduce expression of hZTL1/ZnT5 proteins under zinc supplemented conditions [44] meaning that there is higher expression of zinc transporters during zinc deficiency. Similarly, zinc uptake by human syncytiotrophoblast microvillous membrane vesicles showed that, although gestational age and maternal zinc levels do not alter affinity for zinc, zinc uptake capacity in human placentae is influenced by gestational age and by low levels of maternal serum zinc, presumably to ensure an adequate materno-fetal placental zinc transfer $[45,46]$. Maternal zinc deficiency can reduce trophoblast differentiation, placental weight, and change protein expression, associated with aberrant fetal development [47].

\subsection{Folate}

Folate is an essential vitamin involved in redox processing and one-carbon metabolism required for amino acid metabolism, purine and pyrimidine synthesis. In the cell, 5-methyltratrahydrofolate (5-MTHF - folate) is involved in homocysteine metabolism and formation of S-adenosylmethionine (SAM) vital to methylation of DNA, RNA, protein and phospholipids [48]. Folate required metabolic processes are influenced by folic acid (Vitamin B9 - synthetic form) intake and intake of other B-group vitamins, especially B12 and B6 [49].

Folate deficiency in non-pregnant and pregnant women varies globally, with the daily intake of DFE being below the RDA in low and middle-income countries, particularly in Asia and Africa [50]. Deficiency of folate impairs nucleotide and DNA synthesis that support cell division, leading to megaloblastosis and cell death, especially of highly prolific somatic cells [51]. Periconceptional folate deficiency is linked to disturbances in fertilization, gametogenesis, pre-implantation embryo development and increases in 
follicular homocysteine levels adversely effecting DNA and histone modification of the oocyte [51]. During pregnancy, this inhibition of cell proliferation has profound effects on embryonic neural tube and neural crest cells inducing congenital malformations including neural tube defects (NTD) such as spina bifida and anecephaly as well as neurocristopathies, increasing the risk of premature delivery and miscarriage [48].

Maternal to fetal transfer of folate occurs against a concentration gradient, requiring up-regulation of active folate specific transporters when availability is limited to maintain fetal supply. Maternal dietary intake of folate is critical to ensuring the mechanism of folate transfer to the fetus is unidirectional [52]. Several folate transporters have been isolated from human placental membranes including Folate receptor $\alpha(\mathrm{FR} \alpha)$, proton-coupled, highaffinity folate transporter (PCFT) and the reduced folate carrier (RFC) [53]. Folate transport across human placental syncytiotrophoblasts involves co-localisation of FR $\alpha$ and PCFT on the microvillus plasma membrane, which bind and internalise 5-MTHF. Transport across the basal plasma membrane (BM) into cytotrophoblasts involves and the RFC and may include other mechanisms localised to the BM [53]. Establishment of functional coupling between folate transporters early in pregnancy is crucial to high demands of folate in pregnancy, enabling normal embryogenesis and transplacental, maternal to fetal transport of folate, imperative to early fetal development [53].

\subsection{Vitamin A}

The term Vitamin A refers to a number of fat-soluble retinoid compounds with retinol activity essential to the growth and development of all vertebrate species. These compounds are found in animal products and plant based foods that form part of a healthy diet and yet are known to be deficient in both children and women of reproductive age in 
many places throughout the world $[54,55]$. The biological activity of vitamin A is regulated by oxidised metabolites of retinol such as retinaldehyde (essential to visual processes) and retinoic acid (regulates gene transcription). Inside the cell, retinol is oxidised to form retinoic acid, which regulates transcriptional processes [56]. The metabolism of retinol to retinoic acid is catalysed by enzymes known to be involved in ethanol metabolism, such as alcohol dehydrogenase [57]. As such, retinoic acid signaling can be impaired by ethanol exposure and is thought to be a contributing factor in fetal alcohol syndrome [58]. While Retinol bound RBP levels are known to be carefully regulated in both humans and animals, prolonged vitamin A deficiency, stress, protein restriction or impaired hormonal influences can negatively impact on this carefully controlled system [59]. Conversely excessive maternal vitamin A has been shown to be teratogenic.

While retinoic acid signalling is important in many physiological processes in the adult, it is vital to many stages of embryonic development. Indeed, the term vitamin A deficiency syndrome (VAD syndrome) is well characterised by certain developmental deficits [60]. In contrast, excess retinoic acid is known to induce teratogenic effects with the pattern of birth defects that develop often referred to as retinoic acid syndrome (RAS). Key developmental processes regulated by this micronutrient include, axial polarisation and cellular morphogenesis as well as formation or organs including the kidney, eye, heart, blood vessels, skeletal muscle and reproductive organs [65]. In addition, the process of placentation itself is mediated by retinoic acid signalling [61]. In the human placenta, retinoic acid is important in trophoblast invasion and parturition and regulates production of hormones such as placental lactogens, chorionic gonadotropin hormone and leptin [61]. Maternal retinol binding protein (RBP) is known to be unable to cross the placental barrier but it is likely that placental transport of retinol involves offloading of retinol from maternal $\mathrm{RBP}$ and uptake by fetal RBP within placental tissues or primitive tissues in earlier 
gestation. It is likely that the placenta is in fact a storage site for vitamin A and can to some degree buffer fluctuations in retinol levels to promote fetal development and prevent teratogenesis [59]. It is important to note that regulation of fetal vitamin A supply and cell signalling is regulated by numerous factors with maternal regulation of fetal retinol supply disrupted in a number of pregnancy complications including preeclampsia [62] and gestational diabetes [63].

\section{Micronutrient function during pregnancy}

The role of micronutrients in supporting fetal development and maternal homeostasis extends across the materno-placental fetal axis [3]. Retrospective cohort analysis and in vitro models provide the foundation for much of our existing understanding of the role of micronutrients in supporting pregnancy with limited in vivo evidence to elucidate causal mechanisms in relation to outcomes [64].

\subsection{Maternal}

Maternal micronutrient sufficiency has implications from conception to parturition. Disruption to gametogenesis, fertilization, and early embryonic development have been linked to deficiencies in micronutrients involved in one-carbon metabolism [51]. Beyond the periconception period, early reproductive failure has been associated with deficiencies in folate, vitamin B12, vitamin E, selenium, zinc, copper and iodine [2]. With roles suggested for micronutrients in supporting early pregnancy through the maintenance of cell division, DNA and nucleotide biosynthesis, essential fatty acid synthesis, antioxidant turnover and 
amelioration of oxidative stress, enzyme induction, cell signaling and the maintenance of lipid membrane integrity $[2,3,10,64]$.

Pregnant women with hypothyroidism have a higher incidence of early miscarriage, preterm delivery and complications such as placental abruption and preeclampsia [65]. Many micronutrients are required for normal maternal thyroid function (and consequently normal pregnancy) including iodine [21], magnesium [66], vitamin A [67], Vitamin B-12 [68], zinc and copper [69], and selenium [70]. Selenium supplementation reduces maternal thyroid inflammation and the incidence of hypothyroidism, perhaps due to up-regulation of glutathione peroxidase or iodothyronine deiodinase activities [71]. Recurrent early pregnancy loss and reduced selenium concentrations have been linked in two separate studies $[72,73]$.

Deficiencies in zinc and iron have been associated with alterations in parturition that has been linked alteration in the release of placental corticotropin releasing hormone [74]. Across the course of gestation, micronutrients are important in supporting maternal homeostasis and pregnancy associated hemodynamic, cardiovascular, renal, and gastrointestinal adaptations. However, additional research is required to elucidate mechanisms by which micronutrients may support or respond to these changes [2].

\subsection{Placental}

The placenta plays a vital role in supporting the developing fetus through the supply of nutrients, gaseous and waste exchange, immunologic protection and release of hormones to regulate metabolism, fetal growth, and parturition [75]. Across gestation, functional changes in the placenta occur that accommodate the metabolic demands of the developing fetus, including alterations in the surface area for nutrient exchange, the number and type of 
nutrient transporters, blood flow, metabolic rate, and hormone production $[2,10,75]$. In pregnancies complicated by micronutrient insufficiency, placental nutrient-specific transporters may be up-regulated to maintain fetal supply and transport against the maternal concentration gradient (for example, vitamins B6, B12 and C, folate, iron, zinc), however this is not the case for all micronutrients [10].

Many micronutrients affect endothelial function and can therefore play a role in normal placentation and pregnancy disorders such as hypertension and preeclampsia; for example by reducing the uterine-artery resistance index [76]. Deficiencies of B-complex vitamins and folate are common and result in homocysteinaemia, which can also cause endothelial cell dysfunction [6]. Micronutrients are also key to the synthesis of endogenous antioxidant systems that indirectly affect endothelial function and protect the embryo from oxidative stress. Endogenous antioxidants include glutathione peroxidases (selenium), thioredoxin reductases (selenium) and superoxide dismutases (copper, zinc, and manganese). Micronutrient deficiencies in the periconceptional period and first trimester have been associated with placental oxidative stress and complications of pregnancy such as preterm delivery and preeclampsia [77]. Molecular mechanisms controlling placental vascularization have been associated with micronutrient status. Increased levels of vitamins $\mathrm{D}$ and $\mathrm{E}$ may promote placental expression of angiogenic factors, including vascular endothelial growth factor which may have a role in preeclampsia $[78,79]$. There is also evidence that immune and metabolic functions in the placenta are modulated by vitamin D $[80,81]$

One-carbon metabolism functions as a critical metabolic integrator of nutrient status and is regulated by micronutrients including folic acid, choline, vitamin B12, and omega-3 fatty acids. One carbon metabolism integrates carbon units from amino acids and results in the biosynthesis of lipids, nucleotides and proteins, the maintenance of redox status, and the 
substrates for methylation reactions. These all influence processes in the placenta and play a role in fetal programming [82]. Maternal micronutrient imbalance (excess folic acid with vitamin B12 deficiency) reduced methylene tetrahydrofolate reductase (MTHFR) mRNA and methionine synthase mRNA in rat placenta, but increased mRNA for cystathionine bsynthase (CBS) and Phosphatidylethanolamine-N-methyltransferase (PEMT) as compared to control [83]. Supplementation of pregnant dams with Omega-3 normalized CBS and MTHFR mRNA levels [83]. Therefore the adverse effects of imbalanced maternal diet may be due to altered regulation of genes involved in the one carbon cycle. This cycle is also necessary for DNA methylation and a study has shown that the global DNA methylation levels were higher in women delivering small for gestation age infants as compared to women delivering appropriate for gestation age infants at term [84]. Additionally lower methylation levels were described in preterm placenta [84] that may alter epigenetic programming of the developing fetus.

In utero perturbations that do not lead to overt fetal dysfunction can also have ongoing effects into adulthood. Human and animal studies have demonstrated that females exposed to diets moderately deficient in one or more macro or micronutrient(s) during pregnancy develop subtle placental or fetal adaptations that are not detected at birth. Moderate organ deficits commonly identified in offspring of mothers exposed to insufficient macronutrient levels include reduced nephron endowment [85], lower beta cell mass [86], or cardiomyocyte deficit/immaturity [87]. Micronutrient deficiencies in pregnancy often cause even more subtle long term organ deficits. Moderate magnesium deficiency during pregnancy impairs placental development [88] and, while nephron number is not reduced, induces subtle renal deficits in offspring [89]. Similarly vitamin D deficiency has been shown to not affect offspring cardiomyocyte number or maturity but cause left ventricular hypertrophy in offspring [90]. A recent clinical study similarly demonstrated links between 
vitamin D deficiency and offspring disease; with autism-related traits in children at six years of age associated with low vitamin D during pregnancy [91]. As mentioned above, some of the long term effects of micronutrient deficits on offspring health may be due to altered one carbon metabolism and methylation in utero. Suboptimal folate levels that are not severe enough to cause neural tube deficits have been shown to cause subtle health deficits in offspring. Mice exposed to folate deficiency prior to pregnancy, and throughout pregnancy and lactation, having increased metabolic disease outcomes in offspring when exposed to a high fat diet [92].

\subsection{Fetal}

Micronutrient status has important implications for fetal organ development and function during pregnancy and later in life. An increased risk of cardio-metabolic diseases such as obesity, insulin resistance and dyslipidemia are associated with deficiencies in vitamins $\mathrm{A}$ and $\mathrm{E}$, copper, iron, magnesium and zinc [93]. It has been postulated that such risk may be associated with structural abnormalities of the kidney, pancreas, heart and vasculature $[94,95]$. In relation to neurological development, significant evidence surrounds the role of folate in supporting the development of the neural tube, and deficiencies in micronutrients including iron, zinc, copper, choline, iodine, and vitamin D have been suggested to affect structural brain development, function, and neurochemistry [96]. Despite associations from longitudinal cohort analyses, randomized antenatal micronutrient supplementation trials have failed provided strong evidence to support long-term impacts of supplementation on motor or cognitive function, although benefits were observed in studies where women were poorly nourished $[6,8]$. 


\section{Conclusions}

Maternal under nutrition and associated micronutrient deficiencies remain widespread globally. This is the case for not only the developing world but also the developed world, where the consumption of macronutrient dense, yet micronutrient poor foods may result in a growing population of mothers with suboptimal micronutrient intakes [8]. Although a healthy diet remains the preferred means for meeting micronutrient requirements, the physiological challenges of pregnancy may require additional nutritional support $[2,3]$.

Despite retrospective associations and in vitro evidence to support the benefits of micronutrient supplementation in supporting the maternal, placental and fetal homeostasis during pregnancy, prospective randomised trials have not yet yielded significant evidence to support routine supplementation outside of the developing world [6, 8]. In response, consideration must be given to variations in specific micronutrient supplement preparations, population characteristics, timing of supplement provision and cohort size when designing further studies.

The possibility that trace element supplementation could prevent life-threatening complication of pregnancy and improve longer term outcomes of survival, cognition, and cardio-metabolic risk in offspring warrants further investigation [2, 5]. Larger trials should be undertaken, especially in poorer economies where the intake of trace elements is lower and the need for routine supplementation is greater [6]. Multiple micronutrient supplementation may be a cost effective, applicable, and safe method of improving pregnancy outcomes for millions of women across the globe and it is imperative that we develop our understand of specific micronutrient interactions and the biological mechanisms that underpin their effects. 


\section{Conflicts of interest}

The authors have no conflicts of interest to declare.

\section{Acknowledgements}

This review was generated as part of the Queensland Perinatal Consortium Inaugural Conference held on July 15th 2016 in Brisbane, Queensland Australia. The conference was supported by an Intra-Faculty Collaborative Workshop grant from the Faculty of Medicine and Biomedical Sciences, The University of Queensland. 


\section{References}

[1] Organization WH. The world health report 2002: reducing risks, promoting healthy life 2002: World Health Organization.

[2] Gernand AD, Schulze KJ, Stewart CP, West Jr KP and Christian P. Micronutrient deficiencies in pregnancy worldwide: health effects and prevention. Nature Reviews Endocrinology.

2016;12(5):274-89.

[3] Ramakrishnan U, Grant F, Goldenberg T, Zongrone A and Martorell R. Effect of women's nutrition before and during early pregnancy on maternal and infant outcomes: a systematic review. Paediatric and perinatal epidemiology. 2012;26(s1):285-301.

[4] Roberts JM, Balk JL, Bodnar LM, Belizán JM, Bergel E and Martinez A. Nutrient involvement in preeclampsia. The Journal of nutrition. 2003;133(5):1684S-92S.

[5] Black RE, Allen LH, Bhutta ZA, Caulfield LE, De Onis M, Ezzati M, Mathers C, Rivera J, Maternal and Group CUS. Maternal and child undernutrition: global and regional exposures and health consequences. The lancet. 2008;371(9608):243-60.

[6] Kawai K, Spiegelman D, Shankar AH and Fawzi WW. Maternal multiple micronutrient supplementation and pregnancy outcomes in developing countries: meta-analysis and metaregression. Bulletin of the World Health Organization. 2011;89(6):402-11.

[7] Catov JM, Bodnar LM, Olsen J, Olsen S and Nohr EA. Periconceptional multivitamin use and risk of preterm or small-for-gestational-age births in the Danish National Birth Cohort. The American journal of clinical nutrition. 2011;94(3):906-12.

[8] Haider B and Bhutta Z. Multiple-micronutrient supplementation for women during pregnancy (Review). 2007.

[9] Fowden A and Moore T. Maternal-fetal resource allocation: co-operation and conflict. Placenta. 2012;33:e11-e5.

[10] Sandovici I, Hoelle K, Angiolini E and Constância M. Placental adaptations to the maternal-fetal environment: implications for fetal growth and developmental programming. Reproductive biomedicine online. 2012;25(1):68-89.

[11] Blumfield ML, Hure AJ, Macdonald-Wicks L, Smith R and Collins CE. A systematic review and meta-analysis of micronutrient intakes during pregnancy in developed countries. Nutrition reviews. 2013;71(2):118-32.

[12] Perkins AV and Vanderlelie JJ. Multiple micronutrient supplementation and birth outcomes: The potential importance of selenium. Placenta. 2016.

[13] Bodnar LM, Tang G, Ness RB, Harger G and Roberts JM. Periconceptional multivitamin use reduces the risk of preeclampsia. American journal of epidemiology. 2006;164(5):470-7.

[14] Catov JM, Nohr EA, Bodnar LM, Knudson VK, Olsen SF and Olsen J. Association of periconceptional multivitamin use with reduced risk of preeclampsia among normal-weight women in the Danish National Birth Cohort. American journal of epidemiology. 2009;169(11):1304-11.

[15] Vanderlelie J, Scott R, Shibl R, Lewkowicz J, Perkins A and Scuffham PA. First trimester multivitamin/mineral use is associated with reduced risk of pre-eclampsia among overweight and obese women. Maternal \& child nutrition. 2014.

[16] Scholl TO, Hediger ML, Bendich A, Schall JI, Smith WK and Krueger PM. Use of multivitamin/mineral prenatal supplements: influence on the outcome of pregnancy. American journal of epidemiology. 1997;146(2):134-41.

[17] Stevens G, Finucane M, De-Regil L, Paciorek C, Flaxman S and Branca F. Global, regional, and national trends in total and severe anaemia prevalence in children and pregnant and non-pregnant women. Lancet Global Health [forthcoming]. 2013.

[18] Cao C and O'Brien KO. Pregnancy and iron homeostasis: an update. Nutrition reviews. 2013;71(1):35-51. 
[19] Cao C and Fleming MD. The placenta: the forgotten essential organ of iron transport. Nutrition reviews. 2016;74(7):421-31.

[20] Williams G. Neurodevelopmental and neurophysiological actions of thyroid hormone. Journal of neuroendocrinology. 2008;20(6):784-94.

[21] Zhou SJ, Anderson AJ, Gibson RA and Makrides M. Effect of iodine supplementation in pregnancy on child development and other clinical outcomes: a systematic review of randomized controlled trials. The American journal of clinical nutrition. 2013:ajcn. 065854.

[22] Bidart J-M, Lacroix L, Evain-Brion D, Caillou B, Lazar V, Frydman R, Bellet D, Filetti S and Schlumberger M. Expression of $\mathrm{Na}+/ \mathrm{l}-$ Symporter and Pendred Syndrome Genes in Trophoblast Cells 1. The Journal of Clinical Endocrinology \& Metabolism. 2000;85(11):4367-72.

[23] Mitchell A, Manley S, Morris J, Powell K, Bergert E and Mortimer R. Sodium iodide symporter (NIS) gene expression in human placenta. Placenta. 2001;22(2):256-8.

[24] Manley S, Li H and Mortimer R. The BeWo choriocarcinoma cell line as a model of iodide transport by placenta. Placenta. 2005;26(5):380-6.

[25] Yoshida A, Hisatome I, Taniguchi S, Sasaki N, Yamamoto Y, Miake J, Fukui H, Shimizu H, Okamura T and Okura T. Mechanism of iodide/chloride exchange by pendrin. Endocrinology. 2004;145(9):4301-8.

[26] Wolff J, Chaikoff I, Goldberg R and Meier J. THE TEMPORARY NATURE OF THE INHIBITORY ACTION OF EXCESS IODIDE ON ORGANIC IODINE SYNTHESIS IN THE NORMAL THYROID 1. Endocrinology. 1949;45(5):504-13.

[27] Eng PH, Cardona GR, Fang S-L, Previti M, Alex S, Carrasco N, Chin WW and Braverman LE. Escape from the Acute Wolff-Chaikoff Effect Is Associated with a Decrease in Thyroid Sodium/lodide Symporter Messenger Ribonucleic Acid and Protein 1. Endocrinology. 1999;140(8):3404-10.

[28] Schröder-van der Elst JP, van der Heide D, Kastelijn J, Rousset B and Jesus Obregón M. The expression of the sodium/iodide symporter is up-regulated in the thyroid of fetuses of iodinedeficient rats. Endocrinology. 2001;142(9):3736-41.

[29] Li H, Richard K, McKinnon B and Mortimer RH. Effect of iodide on human choriogonadotropin, sodium-iodide symporter expression, and iodide uptake in BeWo choriocarcinoma cells. The Journal of Clinical Endocrinology \& Metabolism. 2007;92(10):4046-51.

[30] Glinoer D. The regulation of thyroid function in pregnancy: pathways of endocrine adaptation from physiology to pathology. Endocrine reviews. 1997;18(3):404-33.

[31] Labunskyy VM, Hatfield DL and Gladyshev VN. Selenoproteins: molecular pathways and physiological roles. Physiological reviews. 2014;94(3):739-77.

[32] Shchedrina VA, Zhang Y, Labunskyy VM, Hatfield DL and Gladyshev VN. Structure-function relations, physiological roles, and evolution of mammalian ER-resident selenoproteins. Antioxidants \& redox signaling. 2010;12(7):839-49.

[33] Rayman MP. Selenium and human health. The Lancet. 2012;379(9822):1256-68.

[34] Reyes H, Báez ME, González MC, Hernández I, Palma J, Ribalta J, Sandoval L and Zapata R. Selenium, zinc and copper plasma levels in intrahepatic cholestasis of pregnancy, in normal pregnancies and in healthy individuals, in Chile. Journal of hepatology. 2000;32(4):542-9.

[35] Mariath AB, Bergamaschi DP, Rondó PH, Ana CAT, de Fragas Hinnig P, Abbade JF and Diniz SG. The possible role of selenium status in adverse pregnancy outcomes. British journal of nutrition. 2011;105(10):1418-28.

[36] Xu M, Guo D, Gu H, Zhang L and Lv S. Selenium and preeclampsia: a systematic review and meta-analysis. Biological trace element research. 2016;171(2):283-92.

[37] Han L and Zhou S. Selenium supplement in the prevention of pregnancy induced hypertension. Chinese medical journal. 1994;107(11):870-1.

[38] Tara F, Maamouri G, Rayman MP, Ghayour-Mobarhan M, Sahebkar A, Yazarlu O, Ouladan S, Tavallaie S, Azimi-Nezhad M and Shakeri MT. Selenium supplementation and the incidence of 
preeclampsia in pregnant Iranian women: a randomized, double-blind, placebo-controlled pilot trial. Taiwanese Journal of Obstetrics and Gynecology. 2010;49(2):181-7.

[39] Rayman MP, Searle E, Kelly L, Johnsen S, Bodman-Smith K, Bath SC, Mao J and Redman CW. Effect of selenium on markers of risk of pre-eclampsia in UK pregnant women: a randomised, controlled pilot trial. British Journal of Nutrition. 2014;112(01):99-111.

[40] Torre M, Rodriguez A and Saura-Calixto F. Effects of dietary fiber and phytic acid on mineral availability. Critical Reviews in Food Science \& Nutrition. 1991;30(1):1-22.

[41] Shankar AH and Prasad AS. Zinc and immune function: the biological basis of altered resistance to infection. The American journal of clinical nutrition. 1998;68(2):447S-63S.

[42] Caulfield LE, Richard SA and Black RE. Undernutrition as an underlying cause of malaria morbidity and mortality in children less than five years old. The American journal of tropical medicine and hygiene. 2004;71(2 suppl):55-63.

[43] Ford D. Intestinal and placental zinc transport pathways. Proceedings of the Nutrition Society. 2004;63(01):21-9.

[44] Cragg RA, Christie GR, Phillips SR, Russi RM, Küry S, Mathers JC, Taylor PM and Ford D. A novel zinc-regulated human zinc transporter, hZTL1, is localized to the enterocyte apical membrane. Journal of Biological Chemistry. 2002;277(25):22789-97.

[45] Zapata CLV, Trugo NM and Donangelo CM. Zinc uptake by human placental microvillous membrane vesicles. Biological trace element research. 2000;73(2):127-37.

[46] Donangelo CM and King JC. Maternal zinc intakes and homeostatic adjustments during pregnancy and lactation. Nutrients. 2012;4(7):782-98.

[47] Tian X, Anthony K, Neuberger T and Diaz FJ. Preconception zinc deficiency disrupts postimplantation fetal and placental development in mice. Biology of reproduction. 2014;90(4):83.

[48] Antony AC. In utero physiology: role of folic acid in nutrient delivery and fetal development. The American journal of clinical nutrition. 2007;85(2):598S-603S.

[49] Bailey LB and Gregory JF. Folate metabolism and requirements. The Journal of nutrition. 1999;129(4):779-82.

[50] Lee SE, Talegawkar SA, Merialdi M and Caulfield LE. Dietary intakes of women during pregnancy in low-and middle-income countries. Public health nutrition. 2013;16(08):1340-53.

[51] Steegers-Theunissen RP, Twigt J, Pestinger V and Sinclair KD. The periconceptional period, reproduction and long-term health of offspring: the importance of one-carbon metabolism. Human reproduction update. 2013:dmt041.

[52] Yasuda S, Hasui S, Yamamoto C, Yoshioka C, Kobayashi M, Itagaki S, Hirano T and Iseki K. Placental folate transport during pregnancy. Bioscience, biotechnology, and biochemistry. 2008;72(9):2277-84.

[53] Solanky N, Jimenez AR, D'Souza S, Sibley C and Glazier J. Expression of folate transporters in human placenta and implications for homocysteine metabolism. Placenta. 2010;31(2):134-43. [54] Murray JS and White J. Vitamin A supplementation in infants and children. Journal for Specialists in Pediatric Nursing. 2016;21(4):212-7.

[55] Sherwin JC, Reacher MH, Dean WH and Ngondi J. Epidemiology of vitamin A deficiency and xerophthalmia in at-risk populations. Transactions of the Royal Society of Tropical Medicine and Hygiene. 2012;106(4):205-14.

[56] Spiegler E, Kim Y-K, Wassef L, Shete V and Quadro L. Maternal-fetal transfer and metabolism of vitamin $A$ and its precursor $\beta$-carotene in the developing tissues. Biochimica et Biophysica Acta (BBA)-Molecular and Cell Biology of Lipids. 2012;1821(1):88-98.

[57] Feltes BC, de Faria Poloni J, Nunes IJG and Bonatto D. Fetal alcohol syndrome, chemo-biology and OMICS: Ethanol effects on vitamin metabolism during neurodevelopment as measured by systems biology analysis. Omics: a journal of integrative biology. 2014;18(6):344-63.

[58] Feltes BC, de Faria Poloni J, Nunes IJ and Bonatto D. Fetal alcohol syndrome, chemo-biology and OMICS: ethanol effects on vitamin metabolism during neurodevelopment as measured by systems biology analysis. OMICS. 2014;18(6):344-63. 
[59] Spiegler E, Kim YK, Wassef L, Shete V and Quadro L. Maternal-fetal transfer and metabolism of vitamin $\mathrm{A}$ and its precursor beta-carotene in the developing tissues. Biochim Biophys Acta.

2012;1821(1):88-98.

[60] Al Tanoury Z, Piskunov A and Rochette-Egly C. Vitamin A and retinoid signaling: genomic and nongenomic effects. J Lipid Res. 2013;54(7):1761-75.

[61] Comptour A, Rouzaire M, Belville C, Bouvier D, Gallot D, Blanchon L and Sapin V. Nuclear retinoid receptors and pregnancy: placental transfer, functions, and pharmacological aspects. Cell Mol Life Sci. 2016;73(20):3823-37.

[62] Fruscalzo A, Londero AP, Biasizzo J, Bortolotti N, Bertozzi S, Curcio F, Marchesoni D and Driul L. Second trimester amniotic fluid retinol in patients developing preeclampsia. Arch Gynecol Obstet. 2015;291(4):831-6.

[63] Abetew DF, Qiu C, Fida NG, Dishi M, Hevner K, Williams MA and Enquobahrie DA. Association of retinol binding protein 4 with risk of gestational diabetes. Diabetes research and clinical practice. 2013;99(1):48-53.

[64] Christian P. Micronutrients, birth weight, and survival. Annual review of nutrition. 2010;30:83104.

[65] Ohara N, Tsujino T and Maruo T. The role of thyroid hormone in trophoblast function, early pregnancy maintenance, and fetal neurodevelopment. Journal of Obstetrics and Gynaecology Canada. 2004;26(11):982-90.

[66] Moncayo R and Moncayo $\mathrm{H}$. The WOMED model of benign thyroid disease: acquired magnesium deficiency due to physical and psychological stressors relates to dysfunction of oxidative phosphorylation. BBA clinical. 2015;3:44-64.

[67] Farhangi MA, Keshavarz SA, Eshraghian M, Ostadrahimi A and Saboor-Yaraghi AA. The effect of vitamin $A$ supplementation on thyroid function in premenopausal women. Journal of the American College of Nutrition. 2012;31(4):268-74.

[68] Jabbar A, Yawar A, Waseem S, Islam N, UI Haque N, Zuberi L, Khan A and Akhter J. Vitamin B12 deficiency common in primary hypothyroidism. Journal of the Pakistan Medical Association. 2008;58(5):258.

[69] Betsy A, Binitha M and Sarita S. Zinc deficiency associated with hypothyroidism: an overlooked cause of severe alopecia. International journal of trichology. 2013;5(1):40.

[70] Drutel A, Archambeaud F and Caron P. Selenium and the thyroid gland: more good news for clinicians. Clinical endocrinology. 2013;78(2):155-64.

[71] Negro R, Greco G, Mangieri T, Pezzarossa A, Dazzi D and Hassan H. The influence of selenium supplementation on postpartum thyroid status in pregnant women with thyroid peroxidase autoantibodies. The Journal of Clinical Endocrinology \& Metabolism. 2007;92(4):1263-8.

[72] SMITH WBMTS and P BOWEN SIMPKINS J. Selenium and recurrent miscarriage. Journal of Obstetrics and Gynaecology. 1997;17(2):199-200.

[73] Koçak Id, Aksoy E and Üstün C. Recurrent spontaneous abortion and selenium deficiency. International Journal of Gynecology \& Obstetrics. 1999;65(1):79-80.

[74] Allen LH. Biological mechanisms that might underlie iron's effects on fetal growth and preterm birth. The Journal of nutrition. 2001;131(2):581S-9S.

[75] Gude NM, Roberts CT, Kalionis B and King RG. Growth and function of the normal human placenta. Thrombosis research. 2004;114(5):397-407.

[76] Owens S, Gulati R, Fulford AJ, Sosseh F, Denison FC, Brabin BJ and Prentice AM.

Periconceptional multiple-micronutrient supplementation and placental function in rural Gambian women: a double-blind, randomized, placebo-controlled trial. The American journal of clinical nutrition. 2015;102(6):1450-9.

[77] Mistry HD and Williams PJ. The importance of antioxidant micronutrients in pregnancy. Oxidative medicine and cellular longevity. 2011;2011.

[78] Zingg JM, Meydani M and Azzi A. alpha-Tocopheryl phosphate--an activated form of vitamin $\mathrm{E}$ important for angiogenesis and vasculogenesis? BioFactors (Oxford, England). 2012;38(1):24-33. 
[79] Cantorna MT. Mechanisms underlying the effect of vitamin D on the immune system. The Proceedings of the Nutrition Society. 2010;69(3):286-9.

[80] Levine MJ and Teegarden D. 1alpha,25-dihydroxycholecalciferol increases the expression of vascular endothelial growth factor in C3H10T1/2 mouse embryo fibroblasts. J Nutr.

2004;134(9):2244-50.

[81] Liu NQ and Hewison M. Vitamin D, the placenta and pregnancy. Archives of biochemistry and biophysics. 2012;523(1):37-47.

[82] Locasale JW. Serine, glycine and one-carbon units: cancer metabolism in full circle. Nature reviews Cancer. 2013;13(8):572-83.

[83] Khot V, Kale A, Joshi A, Chavan-Gautam P and Joshi S. Expression of genes encoding enzymes involved in the one carbon cycle in rat placenta is determined by maternal micronutrients (folic acid, vitamin B12) and omega-3 fatty acids. BioMed research international. 2014;2014:613078.

[84] Khot VV, Chavan-Gautam P, Mehendale S and Joshi SR. Variable Methylation Potential in Preterm Placenta: Implication for Epigenetic Programming of the Offspring. Reproductive sciences (Thousand Oaks, Calif). 2016.

[85] Cuffe JSM, Walton SL and Moritz KM. Chapter 15 - The Developmental Origins of Renal Dysfunction A2 - Rosenfeld, Cheryl S. 2016. pp. 291-314. Boston: Academic Press.

[86] Portha B, Chavey A and Movassat J. Early-life origins of type 2 diabetes: fetal programming of the beta-cell mass. Exp Diabetes Res. 2011;2011:105076.

[87] Thornburg KL, O'Tierney PF and Louey S. Review: The placenta is a programming agent for cardiovascular disease. Placenta. 2010;31 Suppl:S54-9.

[88] Schlegel RN, Cuffe JS, Moritz KM and Paravicini TM. Maternal hypomagnesemia causes placental abnormalities and fetal and postnatal mortality. Placenta. 2015;36(7):750-8.

[89] Schlegel RN, Moritz KM and Paravicini TM. Maternal hypomagnesemia alters renal function but does not program changes in the cardiovascular physiology of adult offspring. Journal of developmental origins of health and disease. 2016;7(5):473-80.

[90] Gezmish O, Tare M, Parkington HC, Morley R, Porrello ER, Bubb KJ and Black MJ. Maternal vitamin $D$ deficiency leads to cardiac hypertrophy in rat offspring. Reproductive sciences (Thousand Oaks, Calif). 2010;17(2):168-76.

[91] Vinkhuyzen AA, Eyles DW, Burne TH, Blanken LM, Kruithof CJ, Verhulst F, Jaddoe VW, Tiemeier $\mathrm{H}$ and McGrath JJ. Gestational vitamin D deficiency and autism-related traits: the Generation $\mathrm{R}$ Study. Mol Psychiatry. 2016.

[92] McKay JA and Mathers JC. Maternal folate deficiency and metabolic dysfunction in offspring. The Proceedings of the Nutrition Society. 2016;75(1):90-5.

[93] Rao KR, Padmavathi I and Raghunath M. Maternal micronutrient restriction programs the body adiposity, adipocyte function and lipid metabolism in offspring: a review. Reviews in Endocrine and Metabolic Disorders. 2012;13(2):103-8.

[94] Szostak-Wegierek D. Intrauterine nutrition: long-term consequences for vascular health. Int J Womens Health. 2014;6:647-56.

[95] Christian P and Stewart CP. Maternal micronutrient deficiency, fetal development, and the risk of chronic disease. The Journal of nutrition. 2010;140(3):437-45.

[96] Georgieff MK. Nutrition and the developing brain: nutrient priorities and measurement. The American journal of clinical nutrition. 2007;85(2):614S-20S. 